\title{
ATUAR "DE VERDADE". A CONFISSÃO COMO ESTRATÉGIA CÊNICA ${ }^{1}$
}

\author{
Óscar Cornago ${ }^{2}$
}

\section{Resumo}

Este artigo aborda o fenômeno da confissão desde um ponto de vista cênico, destacando seus principais elementos: a comunicação em primeira pessoa, a proximidade espacial, a dimensão física do ato da enunciação e a referência a um passado que é recuperado na forma de experiência. O texto assinala a importância que tem tido os meios de comunicação, especialmente a televisão e o vídeo, na difusão cultural deste modelo de comunicação, e analisa sua utilização na obra de vários criadores de cinema, dança e teatro.

Palavras-chave: teoria do teatro, teoria dos meios, cinema e teatro documental.

A parte final do filme de Abbas Kiarostami, Close-up, de 1991, que está dedicada pelo julgamento de Sabzian, acusado de haver usurpado a identidade do famoso diretor de cinemama iraniano Makhmalbaf. Sabzian - que atua no filme fazendo de si mesmo -, mostra publicamente seu arrependimento por ter atuado como alguém que ele não era, por ter se passado por outro, enganando assim a una família com a promessa de que seus membros participariam no seu próximo filme. Nesta cena, o acusado, uma pessoa de condição humilde, se encontra, por um lado, frente ao juiz, e por outro, frente à câmera de Kiarostami, que previamente explicou-lhe que paralelamente à audiência com o juiz que poderia dirigir-se à câmera para dar outro tipo de explicações - mais pessoais -, de suas ações. Estas últimas seriam gravadas em primeiro plano, ainda que isso seja algo que logo não se manteria.
${ }^{1}$ Tradução do original em espanhol de André Carreira.

2Óscar Cornago

Bernal é pesquisador do Instituto de la Lengua Española do Consejo Superior de Investigaciones Científicas (Madri Espanha). Entres seus livros encontram-se La Vanguardia teatral en España (1965-1975); Del ritual al juego; Discriso teórico y puesta en escena en los años sesenta: la encrucijada de los realismos e Pensar la teatralidad: Migual

Romero Esteo y las estéticas de la modernidad. 
Ao julgamento moral, que deve esclarecer a culpabilidade legal do acusado, se soma um tipo de julgamento estético, que reflete sobre o que foi para Sabzian o acontecimento da atuação. Ambos, no entanto, se focam no que esta atuação teve de verdade e de mentira, e para isso indagam sobre as motivações primeiras da atuação, o que impulsionou Sabzian a se fazer passar por outro. Entre os que assistem o julgamento se encontram os verdadeiros atores do filme, que interpretam os membros da família que foi enganada, o jornalista que trouxe à luz o ocorrido (o fato real no qual se baseia Kiarostami), e que converteu esse assunto em uma útil manchete de imprensa. Depois do veredicto final, da sentença do tribunal iraniano ou do próprio Kiarostami, fica a tomada de posição do espectador que está vendo o filme, surpreendido pela complexidade crescente da situação proposta.

Quando Sabzian admite estar arrependido por sua atuação, o filho da família, aspirante a ator no novo filme deste falso diretor, o acusa de seguir atuando, de atuar não como um diretor famoso, mas sim como uma pessoa honesta para ganhar a simpatia do juiz. Kiarostami pergunta se realmente continua atuando, e ele responde que não. Então conta o que sofreu ao longo de sua vida, se refere a suas experiências pessoais, às situações difíceis que teve que atravessar que ele considera como a base de seu trabalho de atuação. Sou bom ator, diz Sabzian, porque sofri. A verdade dessas experiências sustenta a verdade de sua atuação. E certamente, a julgar pelos resultados, a interpretação de Sabzian durante os três dias que passou na casa da família sob uma falsa identidade não deveu ser ruim.

Esta cena poderia ser entendida como uma alegoria dos espaços de representação do final do Século XX e começo do XXI, e o predomínio que nas estratégias de representação adquiriu um certo tipo de atuação na primeira pessoa cuja verdade (da representação) remete a um plano pessoal. Os meios de comunicação, especialmente desde os anos 60 com a difusão da televisão, o vídeo caseiro e finalmente a tecnologia digital, converteram os palcos em espaços para a confissão, testemunhos pessoais ou testemunhos da história coletiva. Espaços no quais uma pessoa se senta frente a uma câmera e se vê obrigada a enunciar uma verdade pessoal, interior, uma verdade na qual se põe em jogo uma experiência que deve ser verificada. Verdade ou mentira? A verosimilhança da "atuação" frente à câmera busca seu modo de legitimação na experiência à qual apela o relato desse ato de confissão provocado pela presença da câmera. Por outro lado, os modos de reconstrução da história e especialmente as denominadas correntes revisionistas desde os anos 80 também converteram cada vez mais a figura da testemunha em protagonista principal da escritura do passado e da produção de uma verdade. 
Estes palcos saturados de confissões e testemunhos estão pensados como dispositivos de enunciação. A evolução do meio televisivo nos anos 90, com a proliferação de canais privados, a pressão da competição, e o desenvolvimento por outro lado das comunicações pela Internet multiplicaram este tipo de situações. A webcam pode ser considerada como um capítulo a mais, o último capítulo por enquanto, na história das "tecnologias do eu", retomando em um sentido quase literal o termo criado por Foucault nos anos 70 em sua História da sexualidade. Como se explica no começo daquele estudo, seu objetivo não era uma história das práticas sexuais ao longo dos séculos, nem mesmo da permissibilidade social que tiveram os diferentes comportamentos sexuais, mas sim das situações de enunciação construídas em torno desse tema. A partir destes dispositivos de confissão construídos em torno da experiência sexual, Foucault se refere às "tecnologias do eu” ou "estéticas da existência”, situações nas quais o falante remete a uma verdade interior sobre a que se constrói uma identidade que comumente tem que ver com um modo de viver o sexo. Foucault (1977, p. 75) afirma que A confissão da verdade se inscreveu no coração dos procedimentos de individualização por parte do poder, e agrega: $O$ homem, no Ocidente, chegou a ser um animal de confissão. Aos padres, juízes, médicos, professores deve-se somar agora as câmeras de televisão, os vídeos e finalmente as webcams como capítulo último nesta história dos dispositivos para criar verdades e formas de poder. Não é por acaso que os modos de atuação, artísticos ou sociais, que necessitam igualmente deste efeito de verdade, se inspirem também nestes dispositivos de enunciação.

A câmera converte o falante em testemunha de sua própria vida. Ela é convidada a desenvolver um relato em primeira pessoa, que não é somente uma primeira pessoa gramatical, mas também física. Frente à webcam, uma câmera próxima, quase familiar, o falante se vê transformado em sua própria intimidade em um eu-atuo cuja verdade resulta construída em forma de relato, não somente verbal, mas também físico, o relato da experiência quando esta ainda não foi contada, a experiência que fica escrita no corpo, em uma atitude, um modo de atuar, de mover-se, de olhar o outro, de estar frente à câmera. Esses traços físicos são os que convertem a testemunha em uma jóia preciosa do discurso contemporâneo sobre a verdade pessoal ou coletiva, a verdade da história. A aura que rodeia a testemunha não se apóia em sua capacidade de contar o que viu, sofreu ou experimentou, mas sim na própria presença de um corpo que viu isso, sofreu ou experimentou.

De um ponto de vista emocional, não legal, a verdade de um corpo nos afeta, ainda que se resista a ser compreendida, antes mesmo que a história seja referida através das palavras. Frente ao relato que um historiador pode fazer das condições de vida em um campo de concentração, preferimos a narração de alguém que esteve ali, inclusive se pode ser mais parcial ou imprecisa devido ao tempo transcorrido desde o acontecimento ou até ilegível pela idade da 
testemunha. O que importa não é a palavra da testemunha, mas sim a presença desse corpo que esteve ali e agora está aqui, uma "ponte" entre o que foi e o que é, o mito de uma recuperação "real" do passado em tempo presente, a garantia física de uma verdade para cuja construção contribuíram de forma decisiva os meios de comunicação (dessa verdade).

Durante o ato da confissão ou do testemunho aparentam cruzarse, no instante físico da enunciação, o passado com o presente. Este corte da diacronia pelo acontecer sincrônico confere a esta ação uma qualidade maximamente histórica, ainda que como afirma Agamben (2005) a testemunha integral é a testemunha que não pode dar testemunho, que não tem mais a capacidade da palavra, a testemunha que não sobreviveu. Frente a esse outro instante no qual a história assume sua maior visibilidade porque se acaba com a vida do que esteve ali, interrompendo-se sua história, o testemunho do que sobreviveu não deixa de ser a encenação da história em um momento posterior, a ilusão de voltar a fazer presente o passado desde o aqui e agora da palavra como ato (físico) da memória.

Como hipótese de trabalho vamos a considerar este tipo de atuação ainda que se poderia pensar por extensão em qualquer outro modo de atuação - como "tecnologias do eu" ou "estéticas da existência”, dispositivos para a construção de uma identidade que apela para uma verdade pessoal. Foucault define este tipo de estéticas de uma forma ampla como:

práticas sensatas e voluntárias pelas quais os homens não somente fixam regras de conduta, mas também buscam transformar-se a si mesmos, modificar-se seus seres singulares e fazer de suas vidas obras que apresentam certos valores estéticos e respondem a certos critérios de estilo”. (1984, p. 9)

Como parte de um mesmo horizonte cultural e uma mesma necessidade de chegar a uma verdade da atuação, a cena teatral tem utilizado este tipo de práticas enunciativas como suporte de uma dramaturgia que parte do corpo e se dirige de maneira direta ao espectador, simulando a máxima proximidade. Entre a construção desse eu e o espectador, ficam, no entanto, os meios, os meios da imagem, da palavra, e sobre tudo, o meio físico que articula essa palavra. A palavra dita se faz visível como uma ação a mais, uma ação com a qual se trata de criar um tipo de continuidade entre o corpo que está presente ali, testemunha da história, memória física do passado, e o relato construído a partir dessa palavra.

Se à medida que avançaram os anos 90, e sobre tudo já a partir de 2000 chamaram a atenção estes cenários teatrais ocupados por uma palavra (e um corpo) que ensaiaram este tom confessional é porque não se estava 
acostumado a este tipo de comunicação no meio teatral (hoje já não chamaria tanto a atenção), mas também porque continuamos vendo o teatro como algo isolado do resto da paisagem cultural, mediático ou artístico. Na realidade, para alguém que tenha uma experiência mínima com a televisão e as comunicações por computador não chamaria a atenção uma peça teatral que apresente um corpo e uma palavra desde um ponto de vista confessional, como testemunha de uma história, que começa sendo a própria história de si mesmo, a história pessoal do próprio ator. Desde então a cena se encheu de testemunhos em primeira pessoa, construídos sobre a vida pessoal dos próprios atores.

No entanto, esta espécie de "naturalidade" que parece unir a palavra com o corpo sem solução de continuidade não deixa de colocar problemas quando se converte na base de uma verdade, histórica ou pessoal, igualmente natural. O meio artístico, como a reflexão filosófica ao longo do Século XX, tratou dirigir outro olhar sobre este mecanismo de enunciação. Apesar de sua naturalidade, esta situação de enunciação continua tendo um forte caráter cênico, isto é, social, que não passa desapercebido. Ali onde se deixa ver este dispositivo confessional, começando pela televisão e algumas das correntes cinematográficas mais renovadoras a partir dos anos 60, desde a nouvelle vague e todos aqueles movimentos documentais afins ao chamado direct cinema ou cinema verité até poéticas mais recentes como as de Lars von Trier ou o próprio Kiarostami, participam desta tipo de dimensão teatral, ainda que desenvolvida em cada caso de um modo específico.

Um dos últimos exemplos, não por acaso ligado ao meio teatral, o encontramos no documentário de Eduardo Coutinho Moscou, realizado a partir de um processo de montagem de As três irmãs, de Tchekov, pelos atores do grupo Galpão, dirigidos por Enrique Díaz. Nesta peça, continuação de uma reflexão que podemos qualificar de "cênica", iniciada em seu trabalho anterior Jogo de cena (2007), a câmera se fecha com os atores e o diretor nas salas e camarins do teatro do grupo de Belo Horizonte. O objetivo não é gravar a encenação da peça, ou os resultados dos ensaios, mas o processo de construção, de uma maneira fragmentada e desde adentro. Retomando os fantasmas que vagam por esse mundo estático de As três irmãs, a câmera se converte em um dispositivo frente ao qual os atores devem se confessar, contar para a câmera suas lembranças mais antigas, seus medos e seus sonhos, recorrendo a fotografias ou objetos do passado. A câmera de Coutinho, presente de uma forma explícita ao longo de toda a filmagem, se converte em metáfora do próprio procedimento que utiliza a montagem teatral para dar verossimilhança para a atuação. Não se trata unicamente de que os atores encarnem as personagens de Tchekov, mas que através destas eles mesmos se façam presentes na primeira pessoa, com suas experiências, seus desejos e seus sonhos abandonados. A câmera, sobre tudo ao começo do filme, antes de que a parte ficcional termine dominando a filmagem, 
persegue os atores, os mira de perto, cara a cara, nos primeiros planos, como para arrancar-lhes seu segredo, obrigar-lhes a uma verdade pessoal que devem confessar como estratégia para dar realidade ao trabalho de atuação.

Se a partir dos anos 60 o cinema tratou de recuperar através do vídeo uma certa inocência da imagem, perdida com o desenvolvimento da indústria cinematográfica, sobre tudo a partir da introdução do som, a cena tratou de fazer algo parecido buscando a inocência do corpo que atua através da performance. Não é causalidade que o próprio vídeo tenha uma dimensão performativa que se faz presente através do movimento da câmera e que permitiu um intenso diálogo entre este meio e as artes plásticas. $\mathrm{O}$ reencontro com um tipo de imagem que simula uma nova imediatez, mais espontânea, mais pessoal, é paralelo ao reencontro em cena com um corpo que toma distância com respeito ao plano ficcional para deixar-se ver em primeira pessoa, antes que como um corpo com uma experiência íntima da história, como uma identidade construída. O desenvolvimento da performance na cena contemporânea tem a ver com esta busca da experiência, o se queremos da verdade, dessa experiência da que falava o protagonista de Close-up, como base para uma atuação "verdadeira”.

O diretor e crítico de cinema Jean-Louis Comolli (2007) destaca a importância destas estratégias cênicas para a construção de uma atitude crítica na comunicação audiovisual. Este modo crítico tem que ver com outro dos elementos fundamentais do acontecimento cênico, a presença do espectador, que no caso de Coutinho se ressalta através do olhar da câmera, para a qual se dirige a confissão. Esta presença do que olha chegou a ser habitual na paisagem mediática atual. A televisão joga com ela constantemente, a ela se dirigem os apresentadores dos programas, tratando de simular individualidades ali onde só há um comportamento de massas. É esta mesma presença a que se deixa ver de um modo performativo através do vídeo, e toda a genealogia dos equipamentos leves de gravação que transformaram os modos de comunicação audiovisual desde os anos 60. O espectador é o outro, ao que não se conhece, mas que sempre está presente, do outro lado da câmera ou da tela do computador, é o que desencadeia a confissão, o que exige toda a sinceridade. Frente a ele se constrói esse relato de um eu que busca sua verdade última na história de seu próprio corpo, em uma verdade que está por detrás de suas palavras. Para chegar a isso, Comolli reforça a necessidade de se estabelecer uma relação de tensão nesta comunicação com o outro, uma relação de conflito com o que está olhando e ouvindo ao mesmo tempo.

Em 1990 o diretor norte americano Robert Kramer rodou Berlim 10/90, uma obra de tom também confessional construída sobre um único plano sequência de uma hora de duração. Durante este tempo o diretor se fecha com 
a câmera em um banheiro, onde além dele mesmo e da câmera, há uma cadeira e um monitor de televisão pelo qual passam imagens que gravou nos dias anteriores. $\mathrm{O}$ corpo de Krammer, em ocasiões em silêncio, frente à câmera, se deixa ver, dentro do reduzido espaço do banheiro, como uma presença opaca, tranquila, mas cheia de tensões, que se oferece ao mesmo tempo que se fecha frente à câmera e, por consequencia frente ao espectador. Este se faz visível como um intruso neste espaço onde o privado e o político se entre cruzam constantemente. Krammer provêm do movimento contra cultural dos anos 60 . Nos 90 o olhar que projeta esta obra sobre o horizonte histórico do Século XX foi de longo alcance. Esta situação de gravação — ou talvez seja mais correto falar de "enunciação" - é a que o diretor escolhe para fazer um trajeto pela história, ou como dizia Godard, pelas histórias, a história política do Ocidente, mas ao mesmo tempo sua história familiar, porque seu pai, médico judeu, teve que deixar nos anos 30 Berlim, cidade onde Krammer nunca voltou e a que chega então para gravar este trabalho confessional, sua história pessoal e sentimental como diretor de cinema, militante político e companheiro de outra militante que aparece também no monitor de televisão, discutindo com dois amigos sobre os anos da resistência ideológica, dos campos de concentração e das utopias. A história, ou as histórias, chegam até este rincão através da tela de televisão convertidas em fragmentos, gravações em uma fita de vídeo. As ruínas do muro de Berlim, do passado ideológico e de sua própria trajetória pessoal se vem enfrentadas ao seu corpo físico, um corpo que sabe filmar, que poderia ter optado, como se diz no filme, por filmar em outros cenários como Afeganistão, Israel ou Irã mas que decidiu não filmar, ou filmar o mínimo, a si mesmo frente à câmera, frente à história, cara a cara, em uma atitude que participa de uma explícita vontade performativa, ainda que seja pela própria recusa à atuação (fílmica).

Em algum momento deste tempo suspendido, se fala dos livros que estes amigos estão revisando no quarto ao lado e da distância que hoje se abre entre o conteúdo de esses livros (Brecht, Marx, Marcuse) e a experiência ligada a eles. Fala-se da memória presa nesta fita de vídeo que está passando pela televisão e da experiência à que estão se referindo nessas conversações, experiência de sobrevivência em campos de concentração, de resistência física e ideológica. Fala-se também de filmar e de falar, como duas coisas distintas, e do esforço (físico) que implica estar fazendo as duas coisas ao mesmo tempo. Então cita a Wittgenstein: diz Wittgenstein que se escrevesse um livro intitulado $\mathrm{O}$ mundo tal como eu encontrei em algum momento teria que falar de seu corpo e dizer quais partículas dele estão submetidas à sua vontade e quais não. Este seria o método para tratar de isolar o sujeito, ou o que é o mesmo para chegar à conclusão de que em certo modo não há sujeito, ou ao menos este não pode ser nomeado neste livro. Estas confissões apontam a uma história ou 
várias histórias construídas com palavras, mas das que o sujeito, ou um certo sujeito, como diz Krammer, fica excluído. Esse sujeito tem que ver, seguindo a Wittgenstein, com a situação desse corpo tão presente ao longo da gravação, com as histórias referidas por ele e as histórias escritas em seu próprio corpo, convertido em uma capacidade histórica (de filmar) que somente se mostra porque está sendo negada.

Quando Jean-Luc Godard se propõe fazer a(s) história(s) do cinema, sua presença na primeira pessoa, escrevendo ou falando, é também constante. Em um momento afirma algo parecido ao que se dizia em Berlim 10/90: $O$ sentimento que eu tenho da existência não é ainda um 'eu'. Nasce em mim, mas ainda sem mim. E continuando agrega uma pequena reflexão que por seu conteúdo em chave performativa resulta interessante: A verdadeira condição do homem é a de pensar com suas mãos. Em que medida a confissão é também um modo de pensar com o corpo, um pensamento performativo?

Ao longo dos anos 2000 a bailarina brasileira Denise Stutz realizou três solos nos quais expôs uma reflexão sobre seu trabalho, sobre sua história como profissional da dança, que se entrelaça com sua história pessoal. De certo modo, esta necessidade de reflexão, na medida em que dá lugar a um tipo de obra confessional, pode situar-se em paralelo ao trabalho de Krammer. Se este deixou de filmar (sem por isso deixar de fazê-lo) para se apresentar a si mesmo, Stutz deixa de dançar (sem deixar de fazê-lo tão pouco) para apresentar sua história em primeira pessoa, uma história que forçosamente é a história (dança contemporânea) escrita sobre um corpo.

Outro elemento para desenvolver este paralelismo é a tensão com o outro, com o que está olhando, com a que se trabalha em ambas obras. Tanto Krammer como Stutz buscam uma proximidade, não carente de tensões, com o que tem adiante. $\mathrm{O}$ mundo, diz o diretor norte americano, no momento da filmagem está reduzido à minha relação com o outro, eu e isso, ou em palavras de Stutz, você e eu, eu e você, você e eu... lema que se repete de maneira obsessiva ao começo destes 3 solos em 1 tempo (2003-2007), sublinhando, já desde o começo, que o eixo de relações com o outro está no centro desta história profissional e afetiva.

Com uma longa trajetória na dança desde os anos 70, Stutz propõe ao espectador, um outro imaginário, mas ao mesmo tempo real, que ela escolhe entre o público, um pas-à-deux, um solo para dois, na intimidade, e sem se mover da poltrona de onde vai realizar com a presença ilusória desse espectador que a pega, carrega, gira... Depois da dança conta sua história, sua história pessoal e sua história profissional, desde que começou na dança, fundando em 1975 com outros bailarinos o grupo Corpo para passar em 1990 a formar parte da 
Cia. de Lia Rodrigues. No último solo apresenta, como se de um filme mudo se tratasse, uma sucessão de posições físicas, com o corpo nu, nas que se lê como em estampas fixas a história da dança do Século XX.

Em um momento da atuação Stutz lê uma carta pessoal escrita a outros profissionais da dança brasileira. Nela, uma vez mais, os compromissos políticos se misturam com as necessidades pessoais:

Queria dançar algo importante, protestar contra a violência, algum pensamento político ou filosófico, falar da miséria humana. I Mas somente consigo expor minha fragilidade. / Queria dançar para salvar os outros. Mas danço, queridos amigos, para salvar-me a mim.

Uma opção de salvação que passa, no caso da dança de maneira obrigatória, pelo corpo, mas também pelo outro. Não é um corpo que realiza um movimento de forma isolada, mas frente ao outro, um movimento através do outro, como o movimento da câmera de Coutinho buscando um momento de verdade e o movimento de grande parte do cinema de estilo documental desenvolvido desde os anos 60. Também Krammer trata de salvar-se de algum modo frente ao outro, senão de "salvar-se", ao menos de confrontar-se com o outro, ainda que seja através de uma relação tensa que o convida ao mesmo tempo que o excluí. A teatralização da dança é um fenômeno que se acentua ao longo dos anos 90 e do qual participa claramente a proposta de Stutz. Esta teatralização responde também à necessidade de se confrontar com o outro, não somente fisicamente, mas através da palavra, de converter o corpo do bailarino em um corpo social que se dirige ao que tem diante de si, com seus movimentos e com suas palavras, ou com suas palavras transformadas em movimentos e atitudes, que acompanhadas do texto, adquirem de maneira mais clara um tom confessional. Trata-se de um gesto de afirmação e de dúvida ao mesmo tempo, de afirmação de uma necessidade de encontrar um sentido para uma(s) história(s) e de dúvida sobre como fazê-lo. Somente uma coisa fica clara, o caminho é através do outro, a confissão não faz sentido, não pode ter verdade, se não for através da confrontação com quem está em frente, uma necessidade de comunicação explícita distinta da que teve a dança em outros momentos.

Em 2004 o diretor catalão Roger Bernat realizou um trabalho, La, la, la, $l a$, la, no qual parte deste tipo de estruturas cênicas para construir em primeira pessoa o retrato de um artista. Em cena estão ele mesmo, acompanhado de Juan Navarro e Angés Mateus, dois rostos bem conhecidos na criação cênica na Espanha desde meados dos anos 90. Diferentemente das peças anteriores, Roger Bernat retoma este tipo de dramaturgia com um certo grau de ironia, e talvez de cinismo, o que não impede uma forte identificação pessoal e profissional com o 
que está fazendo; assim a peça vai passando por diferentes momentos. Ainda que o ponto de partida é claro: Há interesses em jogo ainda que ninguém os exiba. Esta afirmação inicial põe o espectador em alerta sobre a aparente transparência do que está vendo, uma peça que, como se diz a continuação, não deixa por isso de se apresentar como uma "autópsia” de um corpo, o próprio corpo do artista, um corpo exposto em todos seus detalhes. Nada mais. Uma performance que aspira à transparência. Em torno à pessoalidade do artista contemporâneo, da que se faz responsável o próprio Bernat em primeira pessoa, não deixam de aparecer os temas do egocentrismo, a necessidade de confissão, de salvar o mundo, de referentes culturais, a incapacidade de crescer, a necessidade de público, de que te olhem... em uma lista de características que em um momento da peça se apresentam como o "retrato de um idiota”. Em cena, como se diz no início, só faltam mamãe e papai.

Apesar desta carga de ironia sobre a identidade do artista como imaturo compulsivo, que mais que catalão poderíamos definir como europeu, o tom confessional volta a sublinhar por um lado o corpo e por outro as palavras, que em sua maior parte aparecem projetadas como pensamentos mudos de um corpo que busca uma exposição imediata, cara a cara com o público. O público se faz presente na cena como uma espécie de voyeur em um espaço que faz pensar em um âmbito de privacidade, como o dormitório do próprio artista. Dentro desta disposição, onde tudo fica em uma marcada proximidade, se volta a jogar com a verdade e a mentira do que está ocorrendo em cena, com a aparente naturalidade do que ali se mostra, como se a peça, que recorda a certos programas de televisão, estivesse dizendo ao público "te mostro tudo, mas há algo que você não está vendo”. Para acentuar um sentido de espontaneidade, ligado a uma certa inocência que não deixa de estar sob julgamento pelas próprias reflexões da peça, se recorre uma vez mais a um plano performativo, a uma série de ações físicas que se vão sucedendo ao longo da peça. Como nos casos anteriores, se abre um espaço de tensão que vai desde a presença performativa desses corpos ao esforço por encontrar-lhes um sentido, uma identidade que devem buscar na própria história individual e coletiva.

Mas no caso de Roger Bernat as referências a essa história apenas aparecem, só se vê um vazio cheio de clichês, uma necessidade urgente de encontrar experiências, experiências verdadeiras, sobre as quais construir um relato com o qual se identificar, mas estas experiências se vem limitadas a comportamentos quase infantis, a um sentimento de perda. O conceito de “arte” nasce unido, como lembra Agamben (2004), a este déficit na experiência que está na base da modernidade.

Roger Bernat joga com os estereótipos do artista na sociedade de consumo, a necessidade de transgressão, mas também de subvenções públicas, a necessidade de uma verdade pessoal, de um sentido impossível de alcançar, 
o medo, os limites, mas também o egocentrismo. Tudo isso envolvido em um sentimento de perda, perda dos referentes, de uns contextos mais reais que inventados onde enquadrar-se, que é o que termina predominando na peça. No final do espetáculo, também em um texto projetado, se faz alusão às festas de $1^{\circ}$. de maio, nas quais o pai do artista o levava quando era criança. Fala-se de um sentimento de pertencimento a um grupo, de compromisso com umas ideais, de gente que lutou contra Franco e da idade média das pessoas que seguem indo a essas festas, uns sessenta anos. É quase a única referência em toda a peça à história política. Ao final, Juan Navarro, entre lágrimas, depois de um longo monólogo em que confessa seus desejos mais elementares, enquanto dispara com força uma bola de futebol contra a parede do cenário, convida o público a jogar com ele: Alguém quer jogar futebol comigo? Prometo que deixarei ganhar". A peça acaba com Roger Bernat tocando-se como um menino nas calças.

Se a dramaturgia confessional reenvia o presente a uma experiência original, sobre a que se constrói a atuação desse testemunho da vida, retomando a explicação de Sabzian em Close-up, o cenário de La, la, la, la, la remete a uma falta sobre a que construir essa confissão do artista. No entanto, apesar dessa carência, como na peça de Krammer ou Stutz, o fato da atuação se faz visível por defeito. A busca de uma verdade, a verdade de uma enunciação, aqui e agora, em primeira pessoa, simula deixar de lado o próprio ato da atuação, já seja de filmar, dançar ou interpretar. Em seu lugar fica o espaço da palavra como ação e sua relação sempre difícil com o presente do corpo, a relação, definitiva, da história, do passado, com o presente da cena frente ao público.

Cada um destes exemplos estabelece diferentes modos de relacionar esse presente cênico, onde a palavra confessional se converte no mínimo denominador comum da ação, e os passados aos que remete essa palavra. Em Close-up a atuação de Sabzian busca sua justificação — poderíamos dizer também sua "inocência"-, se não legal ao menos estética — isto é, ética —, nas experiências de uma vida difícil no Irã contemporâneo sem trabalho, casado e com um filho. A câmera de Coutinho, como a de Kiarostami, recorre também a um registro documental para se aproximar da verdade de uma atuação através da memória pessoal e dos sonhos dos atores, tomando como desculpa a interpretação da peça de Tchekov. A ponte entre atuar e não atuar tem que ser construída sobre a verdade dessas experiências de vida confessadas diretamente frente à câmera, frente ao outro.

A presença dos protagonistas destes cenários confessionais faz pensar em uma dimensão potencial que não está sendo atualizada, mas que estaria dentro do possível: um diretor que apenas filma, uma bailarina que apenas dança e um cenário teatral no qual parece que não se quer atuar. Os atos de filmar, dançar ou atuar estão citados quase por ausência, ou ao menos por 
uma fingida ausência, são citados como uma pura potência que se converte em objeto de reflexão frente à história que se está construindo em torno dela, a história do cinema, a história da dança, a história dos artistas cênicos.

Krammer recorre ao seu passado como diretor e militante político para falar de seu presente (atuação) frente a uma câmera quase fixa, à que olha de perto, com a mesma proximidade incômoda com que se convida o espectador. Esse grau mínimo de atuação, encarnado novamente na palavra, está ligado por sua vez a uma vontade declarada de não filmar, de não atuar, para se apresentar ele mesmo, de corpo e palavra. A mesma vontade de "transparência”, como dizia Roger Bernat, guia a obra deste último e de Denise Stutz como estratégia para tratar de construir uma ponte de união que vai desde esse presente cênico desenvolvido frente ao público até o passado feito presente através das histórias que se contam, experiências, recordações, medos e sonhos. Em ambos casos, esse olhar para o passado termina se projetando de forma sempre conflituosa em relação ao outro que está em frente, com seu presente e seu passado próprios, para convidar-lhe a jogar futebol ou dançar, para convidar-lhe a uma viagem pessoal que somente terá sentido se termina se convertendo em um espaço de encontro com o outro, em uma experiência compartilhada no qual o presente se cruza com o passado. Penso que consegui aproximando-me de vocês, relacionar-me melhor, estar mais próximo, diz Denise Stutz ao final de seu trabalho.

No entanto, a experiência não é nunca a experiência de uma certeza, a certeza de uma identificação com um passado ou um artista, mas a de uma fratura com esse mesmo passado, como diz Krammer referindo-se a seus companheiros de militância, a de uma dúvida sobre o modo como esse passado pode seguir atravessando o presente, dando sentido a esta confissão. No ato consciente da tomar a palavra, quando o corpo em lugar de filmar, dançar ou atuar, decide falar, se sublinha um processo de subjetivação, como explica Agamben (2005) se referindo à testemunha, que por sua vez implica um movimento de estranhamento com respeito ao corpo. Este se deixa ver como outra coisa distinta, não reduzida ao relato dessa história, outra realidade só parcialmente contida nessa confissão. Entre o corpo e a palavra se abre um espaço, convertido em espaço de criação artística, de buscas e questionamentos de certezas. E o primeiro que vai ser questionado é a fluidez natural que parece ter entre as coisas, como explica Krammer, entre a subjetividade e a palavra dita, entre a história e a experiência da história.

O ponto de desencontro entre esse corpo e sua história recuperada através da palavra é o momento também da comunicação (cênica) frente ao outro. É nesse momento, frente à câmera, quando Krammer se pergunta pela realidade que seguem contendo esses livros de Marx, Brecht ou Marcuse, 
cenários de obras que já se interpretaram. A cena da atuação, como Berlim para Krammer ou esse banheiro no qual se fecha com a câmera, se converte em uma encruzilhada onde chegam os passados de depois dos anos 70 e 80 , quando ainda parecia que se sabia como havia que atuar, o que havia que fazer na história da dança ou da política ou o não passado de Roger Bernat, a não história dessa espécie de “jovem” Europa amnésica do Século XXI. Neste lugar de tensões, que é também o próprio corpo de quem diz "eu confesso que vivi, que vi, que me disseram, que fiz...", se confronta o passado com o presente, para tentar chegar a uma experiência sobre a qual voltar a construir um relato pessoal. Essa experiência, em todos os casos, passa por um ato cênico (de comunicação) com o outro e o outro, com o que não se conhece, e que não deixa de exigir, como no caso da testemunha aquilo que dizia Gordard da imagem, um ato de fé. Se você crê, é verdade.

\section{Referências bibliográficas}

AGAMBEN, Giorgio. Infancia e história. Destrucción de la experiência y origen de la história. Buenos Aires: Adriana Hidalgo, 2004.

Lo que fica de Auschwitz. El archivo y el testemunha. Homo sacer III. Madrid: Pre-Textos, 2005.

COMOLLI, Jean-Louis. El anti-espectador. Sobre cuatro filmes mutantes. In: Ver y poder. La inocencia perdida: cinema, televisão, ficción, documental. Buenos Aires: Aurelia Rivera Nueva Librería, 2007.

FOUCAULT, Michel. História de la sexualidad. 1. La voluntad de saber. México: Século XXI, 1997.

. História de la sexualidad. II. El uso de los placeres. México: Século XXI, 1984. 